\title{
Respuestas solidarias ante la islamofobia en Barcelona y Vitoria-Gasteiz
}

\section{Nerea González Ortega'}

\section{Jokin Alberdi Bidaguren²}

Resumen: En el presente trabajo vamos a explorar la islamofobia institucional y social a través de los ejemplos de Barcelona y Vitoria-Gasteiz, y las respuestas integradoras y solidarias que tratan de combatirla. Sin idealizar estas últimas, en este trabajo, se pretenden ofrecer pistas para las intervenciones comunitarias ante la creciente construcción esencialista e insolidaria de unas identidades ultranacionalistas cada vez replegadas sobre sí mismas, que consideran a las personas migrantes y musulmanas como enemigas y causantes de los problemas de nuestras sociedades.

Palabras clave: Islamofobia, racismo, aporofobia, ultraderecha, solidaridad, tolerancia.

Fecha de recepción: 9 de febrero de 2019.

Fecha de admisión definitiva: 12 de noviembre de 2019.

\footnotetext{
${ }^{1}$ Doctoranda de Estudios de Desarrollo.

2 Doctor en Ciencia Política y profesor agregado UPV/EHU. HEGOA. Instituto de Estudios sobre Desarrollo y Cooperación Internacional. Universidad del País Vasco / Euskal Herriko Unibertsitatea.
} 


\section{Solidarity as a response to islamophobia in Barcelona and Vitoria-Gasteiz}

\begin{abstract}
In this paper we will explore institutional and social islamophobia by looking at examples from Barcelona and Vitoria-Gasteiz, and investigate the integrative and supportive responses that seek to combat it. Without idealising the latter, this paper aims to offer clues for community interventions in the face of a growth in essentialist, antagonistic and ultra-nationalist identities that are increasingly turned in on themselves, and which consider migrants and Muslims as enemies and the cause of the problems of our societies.
\end{abstract}

Key words: Islamophobia, racism, aporophobia, extreme right, solidarity, tolerance.

\section{Réponses solidaires à l'islamophobie à Barcelone et à Vitoria-Gasteiz}

Résumé: Dans ce document, nous explorerons l'islamophobie institutionnelle et sociale à travers les exemples de Barcelone et de Vitoria-Gasteiz, et les réponses intégratives et de soutien qui cherchent à la combattre. Sans idéaliser ce dernier, ce document vise à offrir des pistes d'interventions communautaires face à la construction de plus en plus essentialiste et peu solidaire d'identités ultra-nationalistes de plus en plus repliées sur elles-mêmes, qui considèrent les migrants et les musulmans comme des ennemis et la cause des problèmes de nos sociétés.

Mots clé: Islamophobie, racisme, aporophobie, extrême droite, solidarité, tolérance.

\section{La construcción del "Otro" y el discurso de la islamofobia}

\section{I.I. ¿Qué es la islamofobia y cómo se ha extendido?}

La islamofobia o "el temor o prejuicios hacia el islam, los musulmanes y todo lo relacionado con ellos" propicia la violación de los derechos humanos y es una amenaza para la cohesión social, en tanto se manifiesta como violencia directa o como racismo y discriminación hacia estos colectivos (Martín Muñoz y Grosfoguel, 2012). Conviene aclarar que no nos estamos refiriendo al pánico que la gran mayoría pueda tener al terrorismo de pretexto religioso, sino que entendemos que una persona islamófoba es aquella que legitima el racismo anti-árabe o anti-musulman.

Tras los atentados terroristas del 11-S del 2001 (y en el Estado español, a partir del 11-M de 2004 en Madrid, y los del 17-A de 2017 en Barcelona), y en la coyuntura del creciente incremento de las desigualdades sociales provocadas por las políticas de austeridad, hay otras interpretaciones de la islamofobia que la asocian a nuevas formas de racismo ligadas a las reconfiguraciones de un capitalismo más violento. Esta islamofobia que define que personas pueden formar parte de la comunidad y quienes no, y que recorta los derechos de las personas musulmanas cala en amplios 
sectores de la sociedad, particularmente, en los más conservadores, y tiene sus expresiones de racismo o islamofobia institucional (Gil-Benumeya, 2018). Según este autor, se acelera una culturalización del racismo que justifica la discriminación de personas y comunidades por sus prácticas religiosas y culturales, en la medida que se generaliza la percepción social de que los migrantes y musulmanes pueden renunciar a sus prácticas culturales o religiosas, en tanto que desprenderse de ellas es una cuestión voluntaria de cada persona. Además de estos prejuicios sociales, Gil-Benumeya explica la islamofobia institucional como el ejercicio del poder de los aparatos ideológicos del Estado que, a través de su rutina burocrática, usa la violencia legalmente autorizada contra estos colectivos árabes-musulmanes, deshumanizándolos y marginándolos.

Sectores laicos rechazan el islam porque es una religión. Desde la óptica securitaria, se la considerada una religión peligrosa. Los nacionalismos no aceptan sus valores culturales por considerarlos extraños. El progresismo lo considera retrógrado. $Y$ desde posiciones anti-sexistas se concibe como una religión y cultura que oprime a las mujeres. En definitiva, esta culturalización del racismo ha contribuido a extender la islamofobia en sectores de derechas y de izquierdas de las sociedades occidentales (Haijat y Mohammed, 2016).

Si bien hay sectores progresistas no racistas que proponen alianzas anticapitalistas con colectivos racializados (Alba Rico, 2015; Karvala, 2016), y otros que, desde la crítica decolonial, apuestan por la autoorganización y consolidación identitaria de las personas racializadas y/o musulmanas (Grosfoguel, 2009), hay también una izquierda no muy alejada de otros postulados más reaccionarios que estigmatizan a las personas musulmanas, y que reclaman la reactivación de las cuestiones de clase y la relegación de los debates sobre el multiculturalismo y otras frivolidades "buenistas" de las otras izquierdas a un segundo plano (Zizek, 2016).

Además, la crisis económica del 2008, y esta nueva fase del capitalismo neoliberal, han intensificado los discursos anti-inmigración y anti-musulmanes. La negativa de la gran mayoría de países europeos que se niegan a acoger personas que huyen de las guerras y de la pobreza, y la irrupción de partidos políticos etno-nacionalistas y anti-europeos de ultraderecha, son una prueba de ello. En el trasfondo, las políticas de austeridad dictadas por los mercados y aceptadas por los gobiernos que han supuesto recortes en los derechos sociales y laborales, han alentado los enfrentamientos entre las clases trabajadoras autóctonas perdedoras de la globalización y las personas migrantes (guerra entre pobres) y un endurecimiento de las políticas de control migratorio y de asilo, y la consecuente vulneración de los derechos de las personas que quieren venir y vivir en la Unión Europea. 
Este nuevo contexto de precarización ha llevado a las clases nativas depauperadas a competir con las personas trabajadoras migrantes propiciando un creciente racismo institucional y el auge de una ultraderecha que alienta un discurso al miedo frente a las personas extranjeras y el islam. La apelación a prejuicios racistas anti-inmigrantes, al desempleo, a la inseguridad ciudadana, junto al auge del nacionalismo favorecieron el surgimiento de una clase social blanca, pobre, que se sentían ignorada por las políicas de acción positiva que beneficiaban a otros colectivos excluidos, y de la "alt-right" o nueva derecha alternativa, que ha actualizado un conjunto de ideologías y formaciones de derechas y extrema derecha, llegando a otorgar el triunfo a Trump, y a extenderse ampliamente por el conjunto de los países europeos.

\section{I.2. Las claves y funcionamientos de la Islamofobia}

Aun siendo conscientes que las comunidades e individuos musulmanes no son el único "chivo expiatorio", en este artículo nos vamos a centrar en el análisis de los clichés, estereotipos y prejuicios, que élites políticas, intelectuales y medios de comunicación construyen sobre el islam. En las líneas siguientes, para conocer los funcionamientos generales de la islamofobia trataremos de ahondar en sus mecanismos y procedimientos.

En este desbroce del argumentario islamófobo, hay que destacar los aportes de Grosfoguel (2014) y otros autores decoloniales, que insisten en que el pensamiento occidental sigue considerando a las personas musulmanas como inferiores racialmente y criaturas violentas, y que la asociación islam-terrorismo, desde los poderes políticos y mediáticos, pretende perpetuar su proyecto de dominación imperial/colonial. La dominante visión liberal-eurocéntrica considera que únicamente los musulmanes occidentalizados pueden aportar a la cuestión de la democracia y los derechos humanos, ya que la filosofía y el pensamiento islámico son incompatibles con la democracia.

Este resurgir de la supremacía cultural blanca, no sería más que la actualización del pensamiento colonizador que asumió que los territorios colonizados deberían ser estudiados y rectificados por el pensamiento moderno y que, posteriormente, derivó en la dominación política, económica y cultural de Occidente sobre Oriente durante el siglo XX (Said, 2003). La modernidad occidental, capitalista, racista y patriarcal sigue mostrándose superior frente a las otras tradiciones culturales, al considerarse la única capacitada para producir conocimiento verdadero, universal y racional. Los estereotipos o modos de representar esas otras sociedades no 
occidentales, más allá de plantear al liberalismo europeo dilemas como el de la segregación o la asimilación, produce una realidad concreta de discriminación o exclusión para esos otros grupos sociales no occidentales (Grovogui, 2006).

Desde otra óptica, la activista y profesora Kumar (2012) subrayó la conciencia islámica de la mayoría musulmana de estar a favor de la justicia, la verdad y los valores humanos, y señaló la necesidad de hacer frente a los cinco mitos contra el islam, que se han ido extendiendo tras el $11-S$, y que están sirviendo de argumentario a los movimientos populistas y racistas de extrema derecha. Esta autora entendía que para reactivar un potente movimiento contra la guerra había que combatir la percepción monolítica, sexista, violenta, irracional y terrorista del islam, y acabar con el estereotipo de que es una amenaza para Occidente.

Alba Rico (2015) destaca los tres principales procedimientos para construir un "otro" manipulable y eventualmente exterminable. El primero consiste en considerar a ese "otro" como unidad, es decir en considerar a todas las personas musulmanas como iguales, sin tener en cuenta sus diferencias geográficas, ni las corrientes y escuelas jurídicas más o menos progresistas o reaccionarias, ni los distintos proyectos ideológicos más o menos incluyentes o excluyentes que defienden. Toda esta compleja realidad se reduce interesadamente a una unidad ficticia con la intención de dominarla y/o controlarla. En definitiva, el cliché de la "invasión musulmana" y la "amenaza islamista" se construyen en base a la omisión de la pluralidad y diversidad del islamismo y el mundo musulmán y árabe. El segundo elemento es la visión negativa del islam que los principales liderazgos transmiten a la sociedad. El islam "es violencia, terrorismo, acoso a mujeres, imposición del velo o, pero, del burka; es desprecio por la vida, lapidación y crimines del honor...", es una unidad negativa en tanto que Occidente es una unidad positiva. Y el tercer mecanismo que se utiliza para construir este enemigo, según este autor, no es que el islam sea solamente una unidad negativa, sino que es una unidad negativa inasimilable. En otras palabras, estos planteamientos racistas sostienen que el islam es irrecuperable, sus miembros inasimilables en las sociedades democráticas modernas y que la confrontación es irremediable.

Otra aproximación es la de Urban y Donaire (2016) que señalan que el argumento de la "amenaza islámica" y la teorización del choque de civilizaciones de Huntington, son empleadas para justificar las intervenciones militares de EE.UU en los países de mayoría musulmana en esta era de la post-Guerra Fría. A su entender, la extensión del miedo y el racismo hacia las personas migrantes y musulmanas entre importantes sectores sociales, y los atentados de AI Qaeda y DAESH, junto a otros elementos como el neopopulismo que vincula la delincuencia y la inseguridad con 
la inmigración, y el mensaje de que "no hay para todos" en el actual contexto de las políticas de austeridad, están sirviendo de coartada para el proyecto de la "Europa Fortaleza", lo que propicia el avance de los partidos de derecha y extrema derecha que alientan el racismo institucional a través del cierre de fronteras.

\section{I.3. La aporofobia y los argumentos de la "ultraderecha"}

Cómo se insinuaba en el inicio de este apartado, no basta con analizar los mecanismos específicos de la islamofobia para comprender las ideas y claves de esta forma de racismo y exclusión. Los debates identitarios sobre el avance de la derecha entre las clases trabajadoras de la década de los 90 , el cuestionamiento de lo "políticamente correcto" y de la diversidad, y la aporofobia pueden ser otras claves para seguir desentrañando la islamofobia.

Desde posicionamientos y puntos de análisis diferentes, destacan una serie de obras anglosajonas que en los últimos años están analizando este resurgir del conservadurismo, y una serie de argumentos y mecanismos que llevan a sectores de clase media blanca y trabajadora a convencerse de que una élite progresista y altiva ha privilegiado a unas minorías mientras que a ellos los abandonan a su suerte.

En un primer bloque sobre el avance de la derecha entre las clases trabajadoras podemos distinguir en la literatura anglosajona varios ensayos de defensa de los intereses de los sectores sociales depauperados blancos y críticas ácidas a los sectores progresistas decadentes que han ninguneado a estos primeros. En el Manifiesto Redneck de Jim Goad (2017) escrito en 1997 se recoge esta frustración $y$, a pesar de sus tintes claramente ultraderechistas, se pueden encontrar algunos elementos de interés para nuestro análisis. Los "negratas" blancos, esos "rednecks" - trabajadores rurales de los EE.UU, que por la constante exposición al sol acaban con sus cuellos enrojecidos, también tienen sentimientos. Los progresistas que defienden el feminismo, el aborto, los colectivos LGTB, la discriminación positiva de las personas negras, y la multiculturalidad y la emigración se ríen, y consideran extraños a estos blancos en su propio país, que realmente son quienes trabajan duro, mantienen los valores cristianos y patrios, y a los que solo les queda emborracharse, drogarse y refugiarse en la cultura paramilitar de las armas $y$, de esta manera, poder ignorar la decadencia de su país. Según este autor el odio, el supremacismo, el racismo, la paranoia de las que se les acusa, son meras excusas para aplacar la potencialidad política de este movimiento. El problema, según Goad, es el progresismo blanco (es el "buenismo"), y la autenticidad está en estas clases 
medias blancas depauperizadas. Dos décadas después, esta frustración clasista ha llevado a la nueva "alt-right" y a Donald Trump al poder.

Un análisis más afinado es el que ofrece el trabajo de Frank (2008). Este autor explica el "contragolpe" o revolución conservadora, y el impacto de las teorías de las dos naciones que solo busca reforzar estereotipos, de cómo las clases populares pasan a apoyar a los Republicanos, a una nueva derecha que se convierte en la defensora de la gente corriente, que no la crítica y que sabe canalizar la rabia de estos sectores a través de la manipulación informativa. La minusvaloración de sus hábitos y a su lealtad a la nación, el rechazo a los posicionamientos progresistas y su anticristianismo, la defensa del aborto, la homosexualidad y de las medidas de discriminación positiva, y una justicia blanda con los criminales han alimentado este "contragolpe". Una revolución conservadora que, paradójicamente, a pesar de presentarse a sí misma como enemiga de una élite (la progresista) a la que considera arrogante, exquisita, moderna y todopoderosa, no es capaz de poner freno a las políticas neoliberales que enriquecen a unos pocos (conservadores), y que va en contra de los intereses de sus propios votantes de clases medias. Es como una revolución francesa a la inversa, donde los "revolucionarios" piden más poder para los aristócratas. Sin descartar que los sectores progresistas son también parte del problema, la cuestión es cómo ante esta falsa "autenticidad", se puede ir construyendo una nueva cultura democrática, más tolerante, y menos racista.

En el testimonio autobiográfico de Andrew Anthony (2009), un periodista inglés de izquierdas que se convirtió a la derecha, tras los atentados del 11 de septiembre, escandalizado por la respuesta del progresismo que se mostraba comprensivo con los terroristas musulmanes y que mantenía que los EEUU se habían merecido este ataque, recopiló el argumentario contra la "estupidez progresista". Este periodista no comprendía la actitud pasiva, derrotista y con sentimiento de culpa del progresismo. No entendía las razones que llevan a sentirse culpable por el pasado colonial, por ser blanco, o ser británico de clase media. Se mostraba contario a cualquier idealización de las minorías como portadoras de valores positivos, y se mostró muy crítico con otros tópicos ideológicos del progresismo. No aceptaba la creencia progresista sobre la armonía de las sociedades multiculturales. Criticó el no cuestionamiento de la discriminación positiva y las descalificaciones racistas sobre quiénes no la defienden. Consideró excesivo el "buenismo" con los delincuentes a los que se les sobreprotege y se los considera víctimas del sistema. Y criticó la excesiva tolerancia con el islam, y esa islamofilia mal entendida, que lleva a confundir la islamofobia con todo aquello que no es favorable al islam. 
Hay otro bloque de reflexiones que se centran más en el retroceso de las concepciones de la justicia y los derechos humanos en estas cuatro décadas de neoliberalismo que explica el surgimiento de fenómenos reaccionarios y la confrontación entre los diferentes sectores empobrecidos. Para entender la ira de los sectores marginados de Gran Bretaña y el incremento de la xenofobia, el racismo y los prejuicios contra las personas migrantes, el rapero y comentarista social inglés "Loki" señala que sus comunidades se han quedado sin centro. El resentimiento abonado por la pobreza provoca ansiedad, depresión, baja autoestima, inseguridad social, enfado, agitación, miedo y resentimiento, en definitiva, una tensión emocional que limita la capacidad de empatía, tolerancia y compasión. Sin embargo, no basta con quedarse en el papel de víctimas y hay que ser conscientes de que han sido las políticas de austeridad las que han despertado el racismo (McGarvey, 2018). Michel Barnier, el negociador jefe europeo del "Brexit" alerta que este cólera social no es exclusivo del Reino Unido, y que hay muchas sociedades en regiones desindustrializadas europeas que se sienten desprotegidas, y en las que se ha extendido la creencia de que la falta de servicios públicos está conectada con los procesos migratorios (Barnier, 2019).

En este largo periodo de políticas de ajuste y austeridad neoliberal, la justicia social y la redistribución han sufrido grandes deterioros, y ha ido creciendo el cerco en la delimitación de los sujetos que son portadores de derechos. De las políticas de acción positiva o acción afirmativa que se extendieron en la década de los 80 y los 90 que trataban de favorecer a grupos minoritarios que históricamente habían sufrido discriminaciones, hemos pasado a la activación de nuevos racismos y discriminaciones, tanto locales como globales, que se han articulado en torno a las inquietudes que han provocado las migraciones internacionales y los temas de seguridad (Wiervioka, 2006).

Los debates sobre la redistribución y los reconocimientos de las diversidades también ayudan a profundizar en algunas de estas explicaciones. Lo cultural e identitario han ido desplazando los debates sobre la justicia y los derechos humanos a un segundo plano. El neoliberalismo progresista, según Fraser $(2008$; 2017) proponía medidas de austeridad que hacían retroceder a las clases trabajadoras, que trataba de compensar con medidas positivas de reconocimiento al multiculturalismo, a las mujeres y a las diversidades sexuales y raciales. El efecto ha sido una nueva concepción de igualitarismo que ha ido estrechando la visión de la justicia y de los derechos, solo para los nacionales de un Estado.

La revuelta de los que padecieron los atropellos del neoliberalismo, está posibilitando el auge de los populismos. La ultraderecha gana adeptos apostando por las teorías 
de la conspiración, el machismo y el tradicionalismo, y lucha contra la diversidad, pero se aprovecha de la trampa que ha supuesto para la izquierda esa misma diversidad que se ha puesto al servicio del mercado (Bernabé, 2018). Según este autor, el descrédito de la democracia como sistema político subyugado a los intereses económicos, la ruptura de identidades que ha producido la globalización, el retroceso del movimiento obrero ante esta restauración neoconservadora, la entrega total de la socialdemocracia al libremercado, y la deriva posmoderna de los movimientos críticos que los ha convertido en una herramienta inútil para hacer frente a los problemas cotidianos de la gente, son señalados como las principales claves que explican este retroceso.

A Zizek (2016) lo que le preocupa es que la sociedad actual sea incapaz de reaccionar a los procesos de fascitización que estamos viviendo, ya que no se están ofreciendo salidas ni a las frustraciones de los jóvenes inmigrantes que no encuentran lugar en las sociedades occidentalizadas, ni a las clases medias y bajas que han visto depauperadas sus vidas tras la reciente crisis económica. No anda con tapujos, ya que denuncia la retroalimentación entre el fascismo islamista y el racismo europeo contra los emigrantes, y critica el "buenismo" de la izquierda, a la vez que denuncia que el nuevo capitalismo global está generando nuevas formas de esclavitud. Augura un futuro oscuro en tanto que, al fracaso liberal, y de las propuestas revolucionarias de izquierdas que le puedan suceder, dejará paso al fascismo.

El concepto de aporofobia acuñado por la filosofa Adela Cortina (2017) también puede ser útil para el análisis que se pretende en este artículo. El rechazo al pobre ○ "aporofobia", combinadas con la frustración y la envida malsana, abonan el terreno al fascismo y al fundamentalismo. Y las migraciones, históricamente, han estado asociadas a la pobreza. Cuando una persona carece de recursos y es pobre dispara el rechazo hacia ella, en tanto que es percibida como una amenaza y un problema. Cortina la define como la fobia hacia el pobre que lleva a rechazar a las personas, a las razas y a aquellas etnias que habitualmente no tienen recursos $y$, por tanto, no pueden ofrecer nada, o parece que no pueden hacerlo.

El empeoramiento de las condiciones económicas, la intolerancia e inseguridad por parte de la sociedad que se empieza a reflejar en el miedo por parte de las personas trabajadoras y las clases medias que ven en las personas inmigrantes una amenaza para su puesto de trabajo, y las actitudes segregacionistas de las clases altas que no quieren mezclarse (De Miguel en Garrido, Torregrosa y Estramiana 1996; Pérez-agote, 1995), están generando una serie de conexiones entre la aporofobia, la xenofobia, el racismo y la islamofobia que hay que seguir investigando 
si queremos comprender las actuales sociedades modernas europeas y avanzar respuestas ante aquellos sectores reaccionarios que justifican un mundo cada vez menos igualitario y con mayores discriminaciones. Para superar la aporofobia, la profesora Cortina propone más educación, eliminación de las desigualdades económicas, la promoción de una democracia más igualitaria y el fomento de la hospitalidad cosmopolita.

\subsection{La islamofobia en España}

Aunque la realidad de la islamofobia en los países europeos es muy diferente, se constata que la mayoría de los movimientos nacionalistas y populistas de derecha y ultraderecha incluyen en sus discursos importantes componentes anti-inmigración y anti-islam, que están incidiendo en las políticas de securitización, militarización y externalización de fronteras europeas para evitar el paso de migrantes, particularmente de cultura islámica. En 28 estados miembros de la UE, hay 39 partidos políticos de extrema derecha, siendo preocupante el crecimiento de estos partidos en Alemania (AfD), Polonia (PiS), Italia (Liga Norte) y Suecia (SD). En 10 países (Alemania, Austria, Dinamarca, Finlandia, Francia, Holanda, Hungría, Italia, Polonia y Suecia) estos partidos xenófobos tienen fuerte presencia desde el 2010, e influyen en las políticas migratorias de sus gobiernos. Y en el caso de Austria, Finlandia e Italia, los partidos de extrema derecha cuentan con ministros en el gobierno (Ruíz Benedicto \& Brunet, 2018).

El triunfo y la irrupción electoral de partidos de nueva y extrema derecha está alimentando la teoría de la islamización de Europa (Mohammed, 2014). En el caso español, en el que las personas musulmanas representan aproximadamente el $4 \%$ de la población total, siendo el $43 \%$ españoles y el $57 \%$ extranjeros principalmente de origen marroquí, este fenómeno de derechización y creciente rechazo a las personas inmigrantes y musulmanas tiene sus particularidades. Vox, un partido ultraconservador y ultranacionalista con un discurso supremacista, poco a poco está lanzando una cautelosa disputa al Partido Popular (PP) y a Ciudadanos (Cs) por los votantes de este espectro político.

La irrupción de Vox ha llegado con sus buenos resultados en las elecciones andaluzas que le ha llevado a convertirse en llave del Gobierno PP-Cs de esta Comunidad Autónoma, y se ha confirmado en las elecciones generales de abril de 2019 que irrumpió con 24 escaños en el Congreso, con más del 10\% del voto total. La consecuencia inmediata ha sido que los partidos conservadores españoles y algunas corrientes de izquierda estén endureciendo sus discursos en torno a la 
cuestión migratoria, y recurriendo con cada vez más frecuencia a argumentos racistas e islamófobos. Prueba de ello es la creación de una corriente por líderes de la izquierda española, siguiendo la estela del movimiento alemán "En pié" surgido en el seno del Die Linke, que propone una vuelta a lo material, una defensa de los "perdedores de la globalización" y de sus puestos de trabajo y una apuesta por una política de fronteras y control migratorio que garantice los sistemas de protección social para los nacionales (El Diario.es, 07.09.2018).

Todo apunta a que en el actual contexto de creciente tensión ante la afluencia de migrantes africanos por parte de determinados sectores sociales, de precarización laboral y pérdida del poder adquisitivo de las personas autóctonas, y de aumento de las desigualdades sociales provocadas por las políticas de austeridad, los partidos políticos españoles, se ven tentados en alentar los discursos del miedo frente a los extranjeros y el islam, y utilizar políticamente los atentados terroristas de pretexto religioso para endurecer las políticas de control migratorio, y para promover recortes en la protección social de las personas migrantes.

Además, en un país como España, con un gran desconocimiento social sobre el islam, se ha dejado demasiado espacio a informaciones sesgadas de los medios de comunicación dominantes, que han difundido una serie de estereotipos y clichés que han contribuido al aumento de la islamofobia. Varios estudios de los discursos e imágenes de la prensa española (Piquer, 2015; Observatorio de la islamofobia en los medios, 2018) identifican los principales estereotipos sobre el islam. Entre ellos, se subrayan: la ausencia de noticias positivas; la identificación de la religión con el terrorismo; la incompatibilidad de la cultura musulmana con la española; la islamización de Europa; el acento en los elementos reaccionarios y radicalizados de esta cultura; y la invisibilizarían y silenciamiento de las otras realidades de esta cultura y religión. Estos clichés coinciden con los procedimientos para construir ese "otro" homogéneo, negativo e inasimilable que mencionaba Alba Rico (2015). Aun así, es importante mencionar que, aunque los medios españoles siguen reflejando un alto nivel de islamofobia en los contenidos de prensa relacionando la religión islámica con elementos negativos, los datos de 2018 han mejorado respecto a los de 2017 (Observatorio de la islamofobia en los medios, 2018).

Esta estereotipación negativa mediática, el racismo institucional y los discursos de las élites de derechas contra estos colectivos están a la orden del día, lo que explicaría que los datos oficiales muestren un aumento de las acciones contra la población musulmana y magrebí en el Estado español. En Cataluña, se percibe un aumento del desprecio hacia el islam. En 2015, el 29,1\% de los incidentes y ataques islamófobos se produjeron en este territorio, en 2016 , fueron el 6,46\% del 
conjunto del Estado, y en 2017, coincidiendo con los atentados de 17 de agosto (17 A) Barcelona y Cambrils volvieron a crecer hasta el 31,88\% (Plataforma ciudadana contra la islamofobia, 2018).

En el caso del País Vasco no parece detectarse un incremento especial, sin embargo, en el caso de Vitoria-Gasteiz, en estos últimos años, los incidentes contra la comunidad musulmana residente en esta ciudad, protagonizados por los discursos discriminatorios hacia la población musulmana e inmigrante del exalcalde Javier Maroto perteneciente al PP, coinciden con un incremento en los ataques de esta naturaleza. Partiendo de las comentadas claves, en los siguientes apartados se van a analizar los principales discursos y episodios anti-musulmanes institucionales y sociales en Barcelona y Vitoria-Gasteiz.

Las vinculaciones de la pobreza, el desempleo, el aprovechamiento de las ayudas sociales, la falta de seguridad con la llegada de migrantes y el "terrorismo de pretexto religioso" realizadas por el exalcalde de Vitoria, Javier Maroto, y el exalcalde de Badalona y líder catalán del PP, Xabier García Albiol, han sido calificadas como propias de políticos xenófobos por varios organismos internacionales (Consejo de Europa, 2018; Comisión Europea contra el Racismo y la Xenofobia, 2018; Ribalaygue, 2018).

Afortunadamente, el combate ciudadano e imaginativo contra el racismo y la xenofobia institucionalizadas en el Ayuntamiento de Vitoria-Gasteiz, provocó que los partidos de la oposición se pusieran de acuerdo para desbancar a Javier Maroto, que había reeditado su victoria en las elecciones del 2015. Algo similar sucedió con Xabier García Albiol, quién a pesar de que su lista fue la más votada en las elecciones municipales de Badalona, no pudo reeditar su mandato como alcalde, ya que la oposición se unió para desbancarlo por sus actitudes y propuestas racistas y xenófobas y su anticatalanismo. No obstante, este artículo no tiene por objeto de estudio lo sucedido en Badalona, sino el caso de Barcelona. El novedoso Plan Municipal contra la islamofobia que se puso en marcha en enero de 2017, que trataba de hacer frente a polémicas vecinales relacionadas con la apertura de mezquitas en algunos barrios de Barcelona y a otros acontecimientos islamófobos, vio condicionado su desarrollo tras los atentados del 17 A de Barcelona y Cambrils. Los ataques y protestas anti-musulmanas de los días posteriores tuvieron su contrapunto en una espectacular respuesta ciudadana en la histórica manifestación contra el miedo y el terrorismo, que tuvo lugar el 26 de agosto de 2017 (López Bargados, 2018), y que merece la pena ser analizada desde la perspectiva del combate al racismo y la islamofobia. 


\section{Islamofobia y las respuestas institucionales y sociales para combatirla en Barcelona}

\section{I. Discursos y episodios anti-musulmanes en Barcelona}

Debido a su implantación geográfica la población musulmana de origen español, magrebí y pakistaní tiene gran presencia en Cataluña principalmente en la provincia de Barcelona (UCIDE, 2019). Son abundantes las expresiones y acontecimientos de islamofobia institucional, de líderes de partidos políticos y de los medios de comunicación que se pueden encontrar en Barcelona. Los años 60-80 suponen un incremento considerable de la población norteafricana (particularmente marroquí) en Barcelona y su metrópoli, la gran mayoría personas en tránsito hacia otros países europeos, que el cierre de fronteras como consecuencia de la crisis económica de los 70, obligó a asentarse a muchas de ellas. Se concentraron inicialmente en Ciutat Vella, y en la medida que se aceleraron los procesos de reagrupación familiar y consiguieron puestos de trabajo más estables se trasladaron a barrios más periféricos, para dispersarse posteriormente por todo Cataluña (Moreras, 2003). Otros movimientos migratorios importantes estuvieron protagonizados por los subsaharianos que, en los años 80 y 90 , fueron a trabajar a los campos catalanes, y con el nuevo milenio otras nacionalidades también fueron llegando a la ciudad (Rumanía, Polonia, Ucrania, Ecuador, Perú, Pakistán...). Es en esta época, cuando se generan los primeros conflictos de convivencia, relacionados con la apertura de mezquitas, y protagonizados por sectores sociales a los que incomoda que estos colectivos minoritarios no adopten las costumbres de las sociedades de acogida.

En 2008, el Gobierno de Cataluña impulsó el Pacto Nacional para Inmigración, que trataba de gestionar estos flujos migratorios y dar pasos para la cohesión social, donde se contemplaban algunas medidas para combatir el racismo institucional y la desinformación de los medios de comunicación. Sin embargo, estos últimos diez años han estado marcados por múltiples ataques a mezquitas, por las actuaciones de algunos ayuntamientos que imponían dificultades adicionales para el empadronamiento, informes desfavorables de convivencia a extranjeros para que no pudieran recibir ayudas sociales, obstáculos a la venta ambulante de inmigrantes y las prohibiciones del burka y el niqab a las mujeres musulmanas. Entre los episodios concretos más destacados señalar: la polémica de 2010 del videojuego del PP catalán, donde su candidata Alicia Sánchez Camacho disparaba contra inmigrantes ilegales; los altercados en Salt tras la muerte de un joven marroquí que huía de la policía; la rumorología iniciada en 2011 sobre la construcción de una 
Gran Mezquita en la Plaza de Toros de la Monumental; la solicitud del líder del PP Alberto Fernández del cierre de todos los oratorios musulmanes sin licencia de la ciudad de Barcelona en 2013; la polémica de la Comunitat Islámica de Nou Barris en 2015 que tenía intención de abrir una mezquita en el barrio de la Prosperitat; los videos de 2015 y 2017 realizados por la Plataforma per Catalunya $(\mathrm{PxC})$ que asocian islam con terrorismo y afirman que la comunidad islámica se beneficia de las ayudas sociales; ... (Garcés, Franco-Guillen \& Elena-Sánchez, 2011; López Bargados, Lundsteen \& Solé, 2016).

Relacionados con estos eventos se pueden encontrar ejemplos de racismo institucional y falta de ética periodística en multitud de declaraciones de muchos políticos y medios de comunicación. Destacamos algunos ejemplos del mencionado, Xabier García Albiol del PP, y Josep Anglada, candidato y fundador de PxC que destacó por sus propuestas de reducir la inmigración a través de repatriaciones y por su particular cruzada contra el islam. En el caso de García Albiol, en 2010 cuando era alcalde de Badalona, acusó a los rumanos gitanos de robar y delinquir, y propuso su expulsión en un panfleto que se distribuyó en esta localidad. En 2011 criticó severamente que las ayudas sociales fueran para los extranjeros. En 2015, tras los atentados yihadistas de París, llegó a asegurar que el multiculturalismo "buenista" había fracasado, y que el islam era inferior y era una amenaza para Occidente, y que los musulmanes deberían aceptar las costumbres españolas. Finalmente, en 2017, tras los atentados del 17-A, contraatacó identificando islam con terrorismo asegurando que es la única religión que "mata en nombre de Dios", exigiendo el cierre de mezquitas y subrayando que los musulmanes se aprovechan de nuestro sistema social.

Josep Anglada consiguió abrirse paso con la fundación de PxC en 2003, siendo un político que ha destacado por sus discursos anti-musulmanes, por considerar el islam como una religión inferior al cristianismo, y que sus practicantes deberían aceptar las costumbres y cultura occidental, su denuncia de la "islamización de Europa, y por la instrumentalización de los atentados de Madrid, Londres y París como estrategia para fortalecer su discurso islamófobo y su influencia en la opinión pública. Este político catalán ha llegado a culpar a toda la comunidad musulmana de la crisis económica, del deterioro de los sistemas de salud y educación públicas, y del aumento de la delincuencia y el tráfico de drogas. Señalar que las últimas contiendas electorales autonómicas, estatales y municipales han dejado unos malos resultados en Cataluña tanto para el PP de Alberto Fernández, como para "Som Identitaris", la nueva marca municipal de Anglada, y para la nueva formación de ultraderecha Vox. 
Estos discursos, acciones y propuestas de los diferentes responsables políticos han tenido un buen caldo de cultivo en el irresponsable tratamiento del islam por parte de los principales medios de comunicación catalanes, que han contribuido a la difusión de los discursos e ideas islamófobas. El tratamiento teológico y sensacionalista ha reforzado los clichés que asocian la religión musulmana al terrorismo y al machismo, y han subrayado su visión más integrista, lo que ha entorpecido la convivencia interreligiosa e intercultural (López Bargados, Lundsteen \& Solé, 2016).

Tras los dos atentados de Barcelona y Cambrils de 2017 se registraron algunos ataques contra centros de culto musulmanes, tanto en Cataluña como en el resto de España. Una veintena de ultraderechistas de la organización Democracia Nacional aprovecharon para manifestarse contra la islamización de Europa (Congostrina, 2017) y se registraron algunos discursos aislados de políticos islamófobos.

\subsection{El Plan de lucha contra el racismo antimusulmán del Ayuntamiento de} Barcelona y la manifestación "Non tinc por" del 26 de agosto de 2017

La realidad del fenómeno migratorio y el peso de la comunidad musulmana en la ciudad de Barcelona favorecieron que ya a principios del milenio la ciudad condal se dotara de algunas estructuras y programas específicos. En 2005, bajo el área municipal de Derechos de la Ciudadanía, Participación y Transparencia, se inauguró la Oficina d'Afers Religiosos. También se constituyó un Comisionado de Asuntos Religiosos, y una Asociación denominada "Stop a Fenómenos de islamofobia-SAFI- que es un colectivo multidisciplinar, plural e interdependiente que se propone como espacio de investigación, formación y denuncia (Lopez Bargados, 2018). Este último colectivo ha elaborado un informe-diagnóstico para la alcaldía de Ada Colau (López, Bargados, Lundsteen \& Solé, 2016) donde se recogen las principales problemáticas y se proponen una serie de recomendaciones relacionadas con: la integración de los jóvenes musulmanes en el sistema educativo y la introducción generalizada de menús halal y de la permisibilidad en el uso del hiyab; la facilitación de la apertura y las reformas arquitectónicas en unos deteriorados y precarios centros de culto (en algunos casos clandestinos); y con los discursos de incitación al odio. Se recomiendan dar facilidades para la construcción de una gran mezquita en Barcelona, aunque se reconoce que su ubicación y financiación siguen siendo polémicas. Y también se proponen una batería de sugerencias para hacer frente a los discursos de incitación del odio. A raíz del informe, el Ayuntamiento de Barcelona diseñó un Plan Municipal de la Lucha contra la islamofobia que tiene tres objetivos y una treintena de medidas que pretenden visibilizar la islamofobia como una forma de discriminación; con- 
trarrestar los estereotipos alrededor del islam y las comunidades musulmanas; y reforzar y poner en marcha los mecanismos necesarios cuando se haya producido una discriminación islamófoba (Ayuntamiento de Barcelona, 2017).

Cómo la mayoría de ellos, este Plan está centrado en hacer frente a las discriminaciones que sufren las personas musulmanas, aunque no se contemplan apenas medidas específicas para combatir las actitudes islamófobas de las personas autóctonas. Tal vez una de las novedades a este respecto, es la elaboración por parte de la Oficina para la No Discriminación (OND) del Ayuntamiento de un protocolo de delitos de odio a partir del seguimiento de casos de islamofobia en coordinación con la Fiscalía. Esta experiencia de Barcelona está siendo referencial para otros municipios en la concreción de políticas públicas orientadas a afrontar problemáticas como la islamofobia.

La otra experiencia anti-islamofóbica que hay que mencionar en este breve repaso tiene que ver con la respuesta ciudadana a los atentados del 17-A. La actitud positiva de la sociedad barcelonesa se distingue de las respuestas ciudadanas que se dieron en otras ciudades que también sufrieron atentados terroristas, en tanto que no hubo declaraciones hostiles al mundo musulmán, o si las hubo fueron anecdóticas. La gran manifestación del 26 de agosto, estuvo precedida por otra que tuvo lugar el 21 de agosto, organizada por la comunidad musulmana, a la que se unieron multitud de personas vecinas y transeúntes donde se corearon mensajes como "no en nuestro nombre", "stop terrorismo" o "islam no es terrorismo" (Iborra, 2017). La distinción entre "ellos" y "nosotros" se iba disolviendo en la evolución de los acontecimientos posteriores a los atentados. En Barcelona, el racismo y la islamofobia han sido combatidos por la propia ciudadanía (Congostrina, 2017).

Al margen de la polémica sobre la instrumentalización de la manifestación contra el terrorismo, y la oposición de las fuerzas independentistas catalanas a la asistencia del Rey Felipe Vl y del entonces Presidente del Gobierno Español, Mariano Rajoy, la gestión política del atentado articulada en torno a los "3 Noes", fue decisiva para evitar caer en la tentación de los discursos dicotómicos y excluyentes que se habían producido en otras manifestaciones europeas (Garcés, 2018).

El "No al terrorismo", el "No al racismo, la xenofobia y la islamofobia" y el "No al miedo" resulto ser una combinación muy interesante. Todas las instituciones, partidos políticos, entidades sociales, gobiernos y organizaciones internacionales coincidieron en el rechazo al terrorismo, de tal forma que el argumento de que algunos sectores izquierdistas no eran igual de exigentes con el terrorismo yihadista que con otras expresiones violentas quedaba anulado. El movimiento antirracista y a favor de 
las comunidad islámica e inmigrante de Barcelona, que participó masivamente en la manifestación, eclipsaron los ataques a mezquitas que se produjeron en tres o cuatro ciudades del Estado, las pequeñas manifestaciones de grupos de extrema derecha y los comentarios islamófobos de las redes sociales. La gran novedad fue el "Non tinc por" (No tengo Miedo) que se extendió durante los días sucesivos y llegó a ser el lema más coreado en la manifestación del 26 de agosto.

Según Garcés (2018) su significado era que, en lugar de dividir la sociedad, estos atentados, habían provocado que la sociedad estuviera más unida que nunca en la defensa insobornable de la libertad y la democracia desde la diversidad de culturas y creencias, y que ni la islamofobia o cualquier otra expresión de racismo o xenofobia no tenía cabida en la sociedad catalana. Declarar que "No tengo Miedo" significaba rechazar, aunque fuera implícitamente, la estrategia del terror de unos y la política del miedo de los otros. La ciudadanía no se centró en considerar al islam como enemigo, sino en la barbarie que se había cometido, y en apoyar tanto a las víctimas y la sociedad barcelonesa como a la comunidad musulmana a la que algunos sectores querían estigmatizar. Esta manifestación se convirtió en uno de esos momentos donde las alianzas y acuerdos entre sectores muy diversos son posibles, un espacio donde personas de espectros ideológicos muy diversos pueden coincidir, y articular mensajes antirracistas y anti-islamófobos, incluso con aquellas personas que, por desconocimiento o manipulación informativa, puedan tener prejuicios con esta comunidad.

\section{Islamofobia y la respuesta social en Vitoria- Gasteiz}

\section{I. Discursos y episodios anti-musulmanes en Vitoria-Gasteiz}

Los estudios del Observatorio Vasco de la inmigración-Ikuspegi subrayan que, en términos generales, la inmigración no resulta un problema para población vasca que, por lo general, tiene una actitud de corte asimilacionista, tendente a un cierto multiculturalismo epidérmico o tolerante de la diversidad más superficial (negocios étnicos, manifestaciones culturales, de ocio...). Aunque, en los últimos años se ha detectado una preocupación por los recelos de sectores de la población autóctona sobre el uso de las ayudas sociales y la asistencia sanitaria por parte de la población extranjera, y sobre la percepción del inmigrante como un competidor en el acceso al empleo (Fernández, Valbuena \& Caro, 2017). El barómetro 2017 de Ikuspegi indica que con la salida de la crisis hay una mejoría en la actitud hacia la población 
migrante, prefiriendo los europeos y mirando con cierto recelo a aquellas personas que tienen culturas y religiones diferentes, siendo los colectivos del Norte de África los que menos simpatías recogen. La población musulmana en el País Vasco es menor en proporción a la de Cataluña, y no es especialmente alta si se compara con otras CCAA. Aproximadamente un tercio de los cincuenta mil musulmanes que hay en Euskadi, residen en Álava, principalmente en Vitoria-Gasteiz (UCIDE, 2016; 2019). Sorprende el apoyo popular que recibe un político que ha sido cuestionado por su xenofobia por diferentes organismos internacionales. Javier Maroto recupera la alcaldía para el PP en 2011 , tras la legislatura del socialista Patxi Lazcoz, y que ya había estado en manos de los populares entre 1999 y 2007. Y como se ha mencionado, si bien sus discursos e iniciativas racistas e islamófobas le pudieron servir para revalidar su victoria electoral en las elecciones de 2015, también fueron la principal causa de que no pudiera hacerse con el bastón de mando de la alcaldía de la capital alavesa.

Los 9 concejales que obtuvieron los populares no consiguieron la mayoría suficiente para gobernar. El jeltzale Gorka Urtaran con 5 concejalas/es, fue elegido alcalde con la suma de los 6 de EH Bildu, 2 de Sumando-Hemen Gaude, y 1 de Irabazi. Subrayar también que Maroto no logró representación para el Congreso por la provincia de Álava en las elecciones legislativas de 2019, siendo la primera vez que sucedía desde 1989.

Este político protagonizó diferentes episodios islamófobos y contra las personas migrantes. Entre ellos caben destacar: la paralización de las obras de la mezquita de Zaramaga en 2011 ; la prohibición de bañarse con velo en las piscinas municipales en 2014; la defensa a un conductor de autobús municipal por negar el acceso a una mujer con burka en 2015; las declaraciones contra las magrebíes acusándolos de abusar de los servicios sociales, y la recogida y la promoción de la Plataforma Ayudas + Justas a nivel del País Vasco en 2015; las declaraciones xenófobas tras el ataque a una lonja que se proyectaba en el barrio de Mariturri en 2016; la crítica a las fuerzas de izquierdas que denunciaron los asesinatos homófobos de Orlando en 2016 y que no denunciaron que se trataba de un atentado de pretexto religioso; y el polémico tweet en el que presentó la estelada (bandera independentista catalana) y la bandera del ISIS a pocos días de los atentados de Barcelona en 2017.

Merece una especial atención el impulso desde la alcaldía de la Plataforma Ayudas + Justas. En noviembre de 2014, casi paralelamente al surgimiento del movimiento ciudadano contra el racismo y la intolerancia que se agrupó bajo el slogan Gora Gasteiz, el alcalde Maroto se lanza a una recogida de firmas para una Iniciativa 
Legislativa Popular (ILP) que trataba de endurecer los requisitos para acceder a la Renta de Garantía de Ingresos (RGI). Para la recogida se pone en marcha esta Plataforma que tiene sedes en diferentes ciudades de los tres territorios históricos. Tras la dimisión de su portavoz de Álava por defraudar al INEM, en abril de 2015 se presentan 41.108 firmas en el Parlamento de Vitoria-Gasteiz, donde meses después PNV, EHBildu y PSE bloquean esta iniciativa de Maroto. No obstante, y ante la nueva aritmética parlamentaria tras las autonómicas de 2016, distintas modificaciones en el sistema de la RGI se discutieron en las negociaciones de los presupuestos anuales del 2017, en tanto que el PNV, además de los votos del PSE para su aprobación, necesita de al menos un voto de los parlamentarios del PP. El argumento de que la RGI era un coladero sin control ha sido uno de los más utilizados con fines electoralistas.

El PP alavés no ha tenido muchos reparos en utilizar la idea de que las personas inmigrantes, especialmente las magrebíes, vienen a aprovecharse de los recursos públicos en un momento de crisis. La guerra entre "pobres" parece ofrecer réditos electorales en Vitoria-Gasteiz en un contexto que el partido más votado en el Estado español ha pasado a ser la última fuerza en el Parlamento Vasco (a excepción de la capital vasca, donde sigue siendo primera fuerza). Un responsable de la gestión de la RGI llegó a afirmar que a Maroto no le preocupa la gestión de la $\mathrm{RGI}$, sino que lo que realmente le importaba era dejar fuera de las ayudas a los magrebíes y a todo lo que representara el islam (Plataforma Ciudadana contra la Islamofobia, 2016)

Los discursos y prácticas islamófobas de la clase política y de los medios de comunicación catalanes, cómo del ex alcalde de Vitoria-Gasteiz se han valido de todos los tópicos populistas y de extrema derecha que se han comentado al inicio de este trabajo. Estos políticos populistas, con la pretensión de ganar votos no tienen reparo en despertar las más bajas pasiones de la ciudadanía, proclamando la inferioridad, holgazanería, irracionalidad y violencia del islam, su homogeneidad, la amenaza que suponen sus costumbres religiosas para los valores democráticos occidentales, la responsabilidad de esta comunidad en el incremento de la delincuencia y el abuso de las ayudas sociales.

Estas nuevas derechas que aparentan ser alternativas no dudan en oponerse a la apertura de nuevos centros de culto, en prohibir expresiones públicas de las costumbres y vestimentas de esta cultura, en exagerar los estereotipos de las mujeres musulmanas o hacer campaña política para que los magrebíes tengan más dificultades para acceder a las ayudas sociales. Se aprovechan de los argumentos aporofóbicos y de la guerra entre pobres, apelando constantemente a la inseguridad 
y a los lemas populistas "de que no hay para todos" y de que "estas personas vienen a traer el mal a nuestras sociedades". Y se presentan como políticos que hablan el lenguaje de la gente llana, y que son los únicos dispuestos a implementar medidas políticamente "incorrectas" que rompen con el discurso "buenista" de la multiculturalidad defendida por los sectores progresistas (Garcés, Franco-Guillen \& Sánchez, 2011). Y aunque en este trabajo no tengamos tiempo de desarrollarlo, y cómo ya se ha mencionado anteriormente, hay que constatar que estas prácticas islamófobas que las derechas españolas parecen copiar de las europeas, también se están abriendo paso en otros espectros ideológicos.

\subsection{La iniciativa Gora Gasteiz y el combate ciudadano contra el racismo y xenofobia institucional}

En Vitoria-Gasteiz, ante las declaraciones e iniciativas racistas del Alcalde Maroto, se fue articulando un movimiento ciudadano muy potente, y que fue la base social que permitió el desalojo del PP del Ayuntamiento. A diferencia del caso de la manifestación del 26 de agosto, esta experiencia optó por la acumulación de fuerzas progresistas con las comunidades migrantes y musulmanas, en lugar de pretender alianzas con sectores populistas de derechas. En cualquier caso, esta plataforma fue un excelente ejemplo donde se pusieron en práctica el conocimiento mutuo entre culturas, la relación directa con los colectivos discriminados, la colaboración multicultural y la celebración de la diversidad.

En 2015, un colectivo irreverente denominado "Maroto tonto del nabo" inició una campaña en las redes y en las calles, con propaganda y "performances" para denunciar las declaraciones xenófobas del alcalde. La asociación de madres y padres de la Escuela Ramón Bajo solicitó a través de un escrito un cambio de actitud del alcalde. Se fue conformando una Plataforma Antiracista formada por distintos colectivos, que organizó una campaña denominada "No en mi nombre" y un escrito que se registró en todos los centros cívicos de la ciudad. A este escrito, le sucedió la presentación pública de la Declaración "Gora Gasteiz. Stop al Racismo" de 78 personalidades alavesas, que coincidió con la conformación de la xenófoba Plataforma Ayudas + Justas promovida por el Alcalde Maroto. Se ponen en marcha diferentes dinámicas e iniciativas populares (carreras pedestres, grupos de teatro, photocall, organizaciones sindicales y comunidades escolares que organizan la marcha de carnaval, charlas sobre islamofobia y medios de comunicación, talleres "Sareak josten-tejiendo juntas" $y$ "te Encuentro", producción de una canción...) que se suman a la campaña de GORA GASTEIZ y que se vuelcan en los preparativos de la gran manifestación del 16 de abril de 2015. Multitud de testimonios de los 
participantes que se recogen en un audiovisual (https://vimeo.com/153104534) que resume la experiencia, apuntan como claves la parte vivencial, intercambio cultural y festiva de estos preparativos.

El objetivo de esta plataforma era la defensa de un modelo de ciudad donde la diversidad estuviera presente y todas las personas tuvieran los mismos derechos. Se reivindicó que tipo de ciudad querían sus protagonistas para Gasteiz, haciendo frente a los discursos islamófobos, xenófobos y racistas que perjudican esa diversidad (Fontaneda, 2016). El siguiente extracto recoge de manera sintética la apuesta por la convivencia, la percepción positiva de los procesos migratorios, la resistencia a ser manipulados informativamente a través de estereotipos y clichés, y la necesidad de una protección social universal que no distinga entre los de aquí - los de allá, y que posibilite la convivencia y el vivir bien para todo el mundo:

Hacemos un llamamiento a luchar por este modelo de ciudad positivo e ilusionante, y a no dejarse arrastrar por discursos interesados que pretenden, mediante información sesgada, alterar la convivencia enfrentando a gasteiztarras contra gasteiztarras. Queremos un modelo de ciudad con un sistema de protección social que tenga como base a la persona, sus diferencias y sus elecciones como garantía de armonía y equilibrio de sociedad. Un sistema que en situaciones de dificultad y riesgo de exclusión social como los actuales, aseguren una vida de calidad para todas y cada una de las personas, permitiendo así el progreso de la sociedad en sí (Gora Gasteiz, 2014).

El 25 de mayo de 2015 Maroto ganó las elecciones, pero el 13 de junio de 2015 Gorka Urtaran del PNV es nombrado alcalde (Fontaneda, 2016). Los diversos talleres, fiestas, campañas de Gora Gasteiz llevados a cabo hicieron frente a las iniciativas xenófobas e islamófobas promovidas sobre todo por el exalcalde de Vitoria (Sr. Maroto), y alentaron un movimiento ciudadano que provocó que los partidos de la oposición se pusieran de acuerdo para desbancar al alcalde que había reeditado su victoria en las últimas elecciones. En las elecciones municipales de 26 de mayo de 2019, el Partido Popular paso de ser la primera fuerza en votos a cuarta.

En Vitoria-Gasteiz, se han puesto en marcha varios planes (Plan Local de Inmigración 2005-2007; y recientemente el Plan de Convivencia y Diversidad de 2017) aunque no son específicos para combatir la islamofobia (Ayuntamiento de Vitoria, 2005, 2016). Recientemente, el Gobierno Vasco ha aprobado un Programa para promover la convivencia junto a la comunidad islámica vasca (2018). En una primera valoración superficial, este documento parece haber puesto más el foco en la convivencia interreligiosa y las medidas de seguridad y prevención socioeducativa ante la radicalización violenta islamista, sin tener en cuenta suficientemente la diversidad de personas que sufren la islamofobia (otros 
colectivos árabes, bereberes, y no practicantes). También hay que destacar las líneas de actuación propuestas, no concretan medidas para combatir los prejuicios y actitudes islamófobas que existen en la sociedad vasca. Cómo se puede apreciar las respuestas de las administraciones vascas para combatir la islamofobia son todavía muy incipientes.

\section{Conclusiones}

Nos gustaría finalizar este análisis sobre la islamofobia y el racismo en VitoriaGasteiz y Barcelona con tres ideas fuerza, y señalando algunas tareas que quedan pendientes. En primer lugar, nos preocupa, particularmente tras la crisis migratoria de 2015, el aumento de la islamofobia y racismo, y el avance de estas ideas en importantes sectores populares. En segundo lugar, subrayaríamos la escasez de intervenciones comunitarias e iniciativas púbicas orientadas a hacer frente al argumentario xenófobo y anti-musulmán. Y en tercer y último lugar, nos gustaría avanzar algunas propuestas para la intervención en esos sectores sociales que cada vez son más esencialistas e insolidarios.

Sobre la preocupación por la creciente islamofobia, tanto las actuaciones de las instituciones públicas como las sociales se centran en los programas de primera acogida y algunas iniciativas interculturales orientadas a la integración, que generalmente solo relacionan a sectores progresistas de la población con los colectivos migrantes y musulmanes. La mirada eurocéntrica sigue estando muy presente, por lo que el respeto a la diversidad y la tolerancia tienen fuertes altibajos. Por poner un ejemplo, según los datos de lkuspegi (2018) en el caso de Vitoria Gasteiz, y a pesar de los acontecimientos que apartaron a Maroto de la alcaldía, se ha dado un retroceso entre las dos posiciones asimilacionistas y multiculturales, a favor de las posiciones más asimilacionistas. Los ataques a los centros de culto, la segregación escolar y otros problemas de convivencia preocupan en la capital vasca. Es necesario repensar y replantear las intervenciones comunitarias para la convivencia y la gestión de la diversidad religiosa.

\section{Sobre la escasa atención a la intervención comunitaria orientada a hacer frente} a las ideas y prácticas anti-musulmanas en los sectores populares, en este trabajo hemos podido constatar algunas realidades y señalar nuevas preguntas para futuras investigaciones. En primer lugar, la escasa investigación sobre el tema. La mayoría de los trabajos consultados están más centrados en el estudio de las comunidades musulmanas y los conflictos de convivencia, mientras que las 
propuestas están más orientadas a dar pasos en la integración e inclusión social de estos colectivos. Salvo algunos estudios sociológicos cuantitativos, son pocas las referencias que tienen por objeto estudiar los comportamientos de las poblaciones autóctonas no musulmanas, y prácticamente son inexistentes los que plantean iniciativas para trabajar con las sociedades de acogida. En segundo lugar, hemos podido apreciar que muchas de las iniciativas de relación entre personas migrantes y autóctonas, de colaboración multicultural, de celebración de la diversidad que se han celebrado en estas ciudades, y en muchas otras, no alcanzan al conjunto de la comunidad, y parecen estar protagonizadas por los sectores progresistas autóctonos y parte de la comunidad migrante de esos municipios. Una tercera constatación preliminar, que requeriría un estudio más profundo, sería que los planes e intervenciones analizadas, apenas incorporan medidas eficaces para hacer frente a las actitudes y episodios islamófobos. Cómo se acaba de apuntar, las intervenciones y propuestas interculturales no alcanzan a importantes sectores sociales, y algunas de las medidas punitivas que se atisban en algunos de estos planes como la tipificación de los insultos y actos islamófobos como delitos de odio no parece que vayan a surtir efecto en la reducción del número de ataques y, por el contrario, sí que pueden plantear serios interrogantes respecto a los límites con los derechos de libertad de expresión y de asociación.

En las valoraciones de los planes institucionales de Cataluña y País Vasco, y las respuestas sociales de la Plataforma Gora Gasteiz y de la Manifestación, se han apuntado algunas de estas ideas. A nuestro entender es fundamental que los planes institucionales y de las iniciativas sociales y ciudadanas realicen propuestas concretas de intervención con los sectores que cada vez se muestran más esencialistas e insolidarios.

Sobre esta última cuestión, nos gustaría subrayar la necesidad de alianzas entre las clases autóctonas depauperadas, grupos sociales que sufren discriminaciones y sectores progresistas que cuestionan el sistema. Hay que explorar fórmulas que acaben con este enfrentamiento entre los sectores sociales autóctonos, que se sienten abandonados por las políticas progresistas, y los sectores marginados (entre ellos las comunidades musulmanas). Para avanzar en esta alianza es fundamental, en primer lugar, desmontar el argumentario que ha sido analizado en este artículo. Para ello es necesario, combatir clichés, argumentos y estereotipos racistas, lo que implica la "desislamización" del fenómeno yihadista para pasar a considerarlo violencia política; la desmitificación de la idea de la incompatibilidad entre islam y democracia; acercarse al "otro" desmontando falsas creencias a través de datos reales que desmientan el abuso de los servicios y ayudas sociales, y la comisión de delitos por parte de estos colectivos de migrantes y musulmanes. También es 
fundamental, prestar más atención a los argumentos de la "guerra entre los pobres", a la desconsideración y abandono por parte de los sectores progresistas de las clases autóctonas depauperadas, y centrar el foco en los factores que originan las desigualdades en nuestras sociedades. El retroceso de las concepciones de igualdad y justicia, el recorte de los derechos y prestaciones sociales que lleva al argumento de "los de aquí primero" tienen que ser combatidos con nuevas propuestas. Hay que fomentar la alianza entre los sectores que sufren los efectos de un capitalismo más salvaje, que precariza los empleos hasta generar una nueva clase de "trabajadores pobres" y que a través del miedo y las técnicas de segregación social y cultural pretende mantener el status quo que solo beneficia a los más ricos.

Aeste respecto, hay que desactivar esta victimización de sectores blancos autóctonos y una falsa "autenticidad" que se ha fomentado por sectores de la nueva derecha y la extrema derecha, y fortalecer un nuevo argumentario de una nueva identidad que conciba la comunidad de una forma más plural, más solidaria y construida sobre la idea de una alianza de clases oprimidas y sectores progresistas que cuestionan este sistema dominante. Para estas alianzas sería fundamental explorar nuevos espacios de interacción, de gente plural, que posibilitaran el contacto, y donde los prejuicios fueran desactivándose. La intervención comunitaria en las escuelas, las asociaciones de madres y padres, asociaciones vecinales y de tiempo libre, clubs deportivos de barrio pueden ser estos lugares de trabajo, donde activar nuevas estrategias para luchar contra el racismo y la islamofobia.

\section{Referencias}

AlbA RICO, S. (2015) Islamofobia, Nosotros, los otros y el miedo. Icaria.

Anthony, A. (2009) El desencanto. El despertar de un izquierdista de toda la vida. Barcelona, Planeta.

Barnier, M. (2019) Entrevista al negociador jefe de la UE para el Brexti. Michel Barnier: Al Reino Unido le cuesta asumir las consecuencias del Brexit. Recuperado el 30 de octubre de 2019 de El País. https://elpais.com/internacional/2019/10/29/ actualidad/1572355961_535142.html.

BERNABÉ, D. (2018) La trampa de la diversidad. Cómo el neoliberalismo fragmentó la identidad de la clase trabajadora. Tres Cantos, Madrid. 
BAUMAN, Z. (2011) Daños colaterales, desigualdades sociales en la era global. Madrid: S.L. Fondo de Cultura Económica de España.

BoureKBA, M. (2018) "Atentados de Barcelona: La explicación imposible, las posibles explicaciones". En M. BOUREKBA, Atentados de Barcelona: reacciones, explicaciones y debates pendientes (pp. 7-19) Barcelona: CIDOB report \#02.

Comisión Europea Contra el Racismo y la XenOfobia (2018) Informe de la ECRI sobre España. Estrasburgo: Consejo de Europa.

Congostina, A. (18 de Septiembre de 2017) Barcelona lucha contra la islamofobia tras los atentados. Recuperado el 21 de julio de 2018, de El País: https://elpais. com/ccaa/2017/09/18/catalunya/1505739417_433143.html.

CONSEJO de EUROPA (2018) Informe de la ECRI sobre España. Comisión Europea contra el racismo y la intolerancia. Estrasburgo.

CORTINA, A. (2017) Aporofobia, el rechazo al pobre, un desafío para la democracia. Barcelona: Paidós estado y sociedad.

El DIARIO.es (7 de septiembre de 2018) El nuevo movimiento alemán En Pie se cruza con las políticas de Salviini: discursos sociales y controles migratorios. Recuperado el 21 de septiembre de 2018, de https://www.eldiario.es/internacional/ movimiento-Pie-Gobierno-Salvini-migratorios_0_811568895.html.

FeRNÁNDEZ, M., VAlBUena, C. y CARO, R. (2017) La evolución del racismo, xenofobia, y otras formas de intolerancia en España. Informe-Encuesta 2015. Madrid. Ministerio de Empleo y Seguridad Social.

FONTANEDA, B. (Dirección) (2016) 'Gora Gasteiz: izan kolore' dokumentala ikusgai [Película].

Frank, T. (2008) ¿ Qué pasa con Kansas? Cómo los ultraconservadores conquistaron el corazón de Estados Unidos. Madrid. Acuerela y A. Machado.

FrASER, N. (2008) Escalas de Justicia. Barcelona, Herder.

- (2017) "Saltar de la sartén para caer en las brasas. Neoliberalismo progresista frente a populismo reaccionario". En AA. VV. El gran retroceso. Un debate internacional sobre el reto urgente de reconducir el rumbo de la democracia Barcelona: Seix Barral. 
Garcés, B., Franco-Guillen, N. y Sánchez-Montijano, E. (2011) "Entre la exclusión y la inclusión. Los discursos políticos en las elecciones municipales de 2011 en Cataluña". Anuario de la Inmigración en España, 2011 (pp. 264-285).

GarCÉs, B. (2018) "17A: Barcelona cambia de guión". En M. BoureKBA, Atentados de Barcelona: Reacciones, explicaciones y debates pendientes (pp. 21-32) Barcelona: $\mathrm{CIDOB}$ report \#02.

Garrido, A., Torregrosa, J. y Estramiana, J. (1996) Psicología social aplicada. Madrid: McGraw-Hill.

GIL-Benumeya, D. (2018) "Viejas políticas y nuevos racismos. La izquierda frente a la islamofobia". Revista de estudios internacionales Mediterraneos, REIM, N ${ }^{\circ} 24$, 849-709-108.

GIMÉNEZ PÉREZ, F. (2009) "Memorias de un progre britónico que queda desengañado". Sobre el desencanto, de Andrew ANTHONY, Planeta, Barcelona 2009. Disponible en: http://nodulo.org/ec/2009/n091p14.htm.

GOAD, J. (2017) Manifiesto Redneck. De cómo los hillbillies, los hicks y la basura blanca se conviertieron en los chivos expiatorios de Estados Unidos. Salamanca. Dirty Works.

Grosfoguel, R. (2009) "Izquierdas e izquierdas Otras: entre el proyecto de la izquierda eurocéntrica y el proyecto transmoderno de las nuevas izquierdas descoloniales", Tabula Rasa, n 11, julio diciembre, 9-29.

- (2014) "Las múltiples caras de la islamofobia". De Raíz Diversa, vol. 1, núm. 1 abril septiembre, 83-114.

Grovogul, S. N. (2006) Beyond Eurocentrism and Anarchy. Memories of International Order and Institutions. Nueva York: Palgrave-MacMillan.

Hajuat, A. y Mohammed, M. (2016) Islamophobie. Comment les élites françaises fabriquent le <<problème musulman >>, París, La Dècouverte.

IKUSPEGI (2017) Barómetro 2016. Percepciones y actitudes hacia la población de origen extranjero. Bilbao: Servicio editorial de la Universidad del País Vasco.

- (2018) Barómetro 2017. Percepciones y actitudes hacia la población de origen extranjero. Bilbao: Servicio editorial de la Universidad del País Vasco. 
KARVALA, D. (ed.) (2016) Combatir la islamofobia: una guía antirracista. Barcelona, Icaria.

KUMAR, D. (2012) Islamophobia and the politic of empire. Chicago: Haymarketbooks.

López Bargados, A., Lundsteen, M. y Solé, A. (2016) La práctica religiosa de les comunitats musulmanes de Barcelona. Expresión i problematàtiques. Barcelona, Stop als Fenomens Islamòfobs.

López Bargados, A. (2018) "Barcelona, ¿̇ciudad islamófoba? Variaciones sobre las políticas seculares y el "problema musulmán"". Revista de Estudios Internacionales Mediterráneos, 89-108.

Martín MuÑOz, G. y Grosfogel, R. (2012) La islamofobia a debate: la genealogia del miedo al islam y la construccion de los discursos antiislamicos. Madrid: Casa Arabe.

McGarVEY, D. (2018) Safari en la pobreza. Entender la ira de los marginados en Gran Bretaña. Madrid: Capitán Swing.

MORERAS, J. (2003) "Marroquíes en Cataluña". Atlas de la inmigración marroquí en España, 305-312.

OBSERVATORIO del IsLAM EN LOS MEDIOS (2018) Una realidad incontestable: Islamofobia en los medios.Fundación Al Fanar e IEMed.

Pérez-Agote, A. (1995) "Reflexiones sobre el multiculturalismo que nos viene". En E. LAMO DE ESPINOSA, Ciudadania, estados, ciudadanos: Una aproximación al multiculturalismo en Europa (pp. 81-98) Madrid: Alianza.

PIQUER MARTí, S. (2015) "La islamofobia en la prensa escrita española: aproximación al discurso periodístico de El País y La Razón". Dirāsāt Hispānicas n ${ }^{\circ} 2$ - 2015: 137-156.

Plataforma Ciudadana Contra la Islamofobia (2016) Informe anual. Islamofobia en España 2015. España.

- (2017) Informe anual. Islamofobia en España 2016. España.

- (2018) Informe anual. Islamofobia en España 2017. España. 
RibalAYGue, J. (28 de febrero de 2018) El Consejo de Europa pone a Albiol y Maroto como ejemplos de políticos xenófobos. Recuperado el 20 de julio de 2018, de El Mundo: http://www.elmundo.es/cataluna/2018/02/28/5a96939dca47 $41191 \mathrm{~d} 8 \mathrm{~b} 4616 . \mathrm{html}$.

Ruiz Benedicto, A. y Brunet P. (2018) Levantando Muros. Políticas del miedo y securitización en la Unión Europea, Barcelona, Centre Delás, Tni, y Stop Wapenhandel.

Safi - Stop Als FenÒmens Islamòfobs $(s, f)$ Safi - Stop Als Fenòmens Islamòfobs. Recuperado el 26 de Agosto de 2018, de https://saficatalunya.webs.com/qui-som.

SAID, E. (2003) Orientalismo. Barcelona: Debolsillo.

UCIDE (2016) Estudio demográfico de la población musulmana. Explotación estadística del censo de ciudadanos musulmanes en España referido a fecha 31/12/2016. Unión de comunidades islámicas de España.

- (2019) Estudio demográfico de la población musulmana. Explotación estadística del censo de ciudadanos musulmanes en España referido a fecha 31/12/2018. Unión de comunidades islámicas de España.

URBÁN, M. y DONAIRE, G. (2016) Disparen a los refugiados: La construcción de la Europa Fortaleza. Barcelona: Icaria.

WieRVIORKa, M. (2006) "La mutación del Racismo", Migraciones 19, 151-163.

Zizek, S. (2019) La nueva lucha de clases. Los refugiados y el terror. Barcelona, Anagrama. 